\title{
Efficiency Change, Technological Progress and Sources of Long Term Agricultural Productivity Growth in Selected MENA Countries
}

\author{
Boubaker Dhehibi, Aymen Frija, Aden Aw-Hassan \\ Resilient Agricultural Livelihood Systems Program (RALSP), International Center for Agricultural Research in \\ the Dry Areas (ICARDA), Amman, Jordan \\ Email:b.dhehibi@cgiar.org, a.frija@cgiar.org, a.aw-hassan@cgiar.org
}

How to cite this paper: Dhehibi, B., Frija, A. and Aw-Hassan, A. (2018) Efficiency Change, Technological Progress and Sources of Long Term Agricultural Productivity Growth in Selected MENA Countries. American Journal of Industrial and Business Management, 8, 1843-1860. https://doi.org/10.4236/ajibm.2018.88125

Received: March 13, 2018

Accepted: August 27, 2018

Published: August 30, 2018

Copyright ( 2018 by authors and Scientific Research Publishing Inc. This work is licensed under the Creative Commons Attribution International License (CC BY 4.0).

http://creativecommons.org/licenses/by/4.0/

\section{cC) (i) Open Access}

\begin{abstract}
We investigate the factors that affect total factor productivity growth in MENA countries. To this end, we start first by examining levels and trends in agricultural outputs and productivity growth using Torqnovist Indexes and then computing Malmquist Indexes for three MENA countries representing three different agro-ecological areas; irrigated (Egypt), rainfed (Tunisia) and rangeland (Jordan) over the period 1961-2012. We make use of data drawn from the Food and Agriculture Organization (FAO) dataset. The advantage of this decomposition is that allows decomposing TFP into its two components, namely technical efficiency (TEF) and technological change (TECH). The analysis was complemented by econometric regression of the obtained TECH, considered as the most important long-run driver of TFP growth, scores on a set of potential explicative variables. Turning to the determinants of the components of TECH, the paper findings showed that TFP can be increased due to the increasing in human capital, share of the main crop harvested in each country, and resource reallocation-agricultural employment share. The main implication policy of this research is that growth and determinants of TFP are essential for assessing the country past and potential economic performance, and the gains in TFP drive gains in income and growth.
\end{abstract}

\section{Keywords}

Total Factor Productivity, Agricultural Growth, Tornqvist Index, Malmquist Index, Growth Determinants, Tunisia, Jordan, Egypt

\section{Introduction}

Productivity growth in agriculture and its determinants have been the subject matter for deep research over the last decades. Agricultural and development 
economists have examined the sources of productivity growth and differences over time among different countries and regions. Growth of agricultural productivity is considered as backbone of sustainable poverty reduction in developing countries such as Middle East and North African Countries (MENA).

Productivity growth in the agricultural sectors of these countries is essential. Trends of economic development show that differences in poverty reduction rates over the past decades have been closely related to differences in agricultural performance-particularly the rate of agricultural productivity growth [1]. Agricultural outputs should grow at a rate that meets the growing food demands due to the increasing population growth in this challenging region. This growth should also consider sustainable use of resources particularly water and land, which are facing serious challenges of scarcity, loss of fertility, desertification, and others.

[2] examined the impact of climate variables on agricultural productivity in several MENA countries. The findings of this study suggested that precipitation, drought, and heat are considered key factors for declining the productivity of the agriculture sector. In fact, several avenues to stimulate agricultural TFP growth need in depth research to enhance agricultural production in the mentioned countries [3] [4].

Agriculture plays an important role in the economies of most of the non-oil rich countries of the Middle East and North Africa region. Despite the fact that MENA is the most water-scarce and dry region in the world, many countries in the region, especially those around the Mediterranean Sea, remain highly dependent on agriculture [5]. Given that agricultural output growth is usually due to three factors, including area, and yield growth, and price changes, some questions thus arise about the future performances of the agricultural sectors and their potential in assuming growth. Yield growth is generated by both inputs and productivity (TFP) growth. In their study, [6] defined TFP growth as the combination of two resources: technical efficiency (TE) and technical change (TCh). They argue that TFP growth pattern is the trade-off between TE and TCh and in order to achieve the optimal growth of this productivity, the share between these factors must be assessed and harmonized.

The study examines trends in agricultural productivity over the last six decades. Particularly, investigates the most important factors explaining the TFP growth in the agriculture sector of the mentioned countries; second estimating technical and efficiency changes and determining the magnitude of their contribution to the overall TFP growth. Besides this, other objectives of this paper will look at factors that determine TFP growth. Knowing what factors will influence TFP growth can lead to useful policy recommendations that allows enhancing and sustaining agricultural productivity growth on in the future.

The remainder of this paper is divided into six major sections. Section 2 presents the methodologies used to measure TFP, with special emphasis on the TFP indices and the main expected drivers of TFP growth. Section 3 outlines the 
data used and its main resources. Results and discussion of the main findings on TFP measurement, TFP decomposition and TFP determinants are presented in the fourth section. Finally, Section 5 presents the conclusions and policy implications.

\section{Productivity Measures and Methodology}

\subsection{Conceptual Fmework}

According to [7], there are basically two approaches to measure the TFP growth: the frontier and non-frontier approaches (Figure 1). In fact, each of these approaches is further divided into parametric and non-parametric techniques. In the called frontier approach, best observed combinations of inputs-outputs are estimated and compared to the rest of the sample observations (cross sectional or time series). Observations corresponding to the best obtainable output given constant inputs and prices levels are identified in order to compare the rest of observations to the best obtainable output ${ }^{1}$.

TFP growth as obtained from frontier approach consists of outward shifts of the production function resulting from technological progress, and from technical efficiency improvement, which are related to enhancements in farmers' technical skills through time. The non-frontier approach assumes that firms are technically efficient, and therefore technological progress determine shift in the production function or TFP growth [7]. Absence in technical efficiency in the non-frontier approach is justified by [8] which arguing that in the long-run firms learn management practices to adjust costs and inputs so approaching higher and higher levels of efficiency. The non-parametric frontier approach, which is typically statistical, evaluates firms to an average producer, and hence it is characterize as a central tendency approach. Frontier and non-frontier approaches can be estimated by parametric and non-parametric methods (Figure 1).

In this paper, a combination of an index method (Torqnovist-Theil Index) together with a nonparametric approach (Malmquist Index). While the Torqnovist-Theil Index allow for accounting productivity growth through both inputs and outputs indexes, the Malmquist index allow however to decompose this growth into different technological and non technological sources.

\subsection{Total Factor Productivity Growth in Agriculture: Torqnovist-Theil Index}

As first step, in this research the Tornqvist-Theil index have been used to examine TFP growth through the three selected MENA countries. This following step consist on the construction of both aggregate output and input indexes. By using this framework, TFP growth is considered as equivalent to growth in technical change ${ }^{2}$. The Tornqvist output, input and TFP index are expressed as follows:

${ }^{1}[8]$.

${ }^{2}$ More explanations on the use of Tornqvist Index Indicator framework are presented in [9] [10] [11] [12] [13]. 


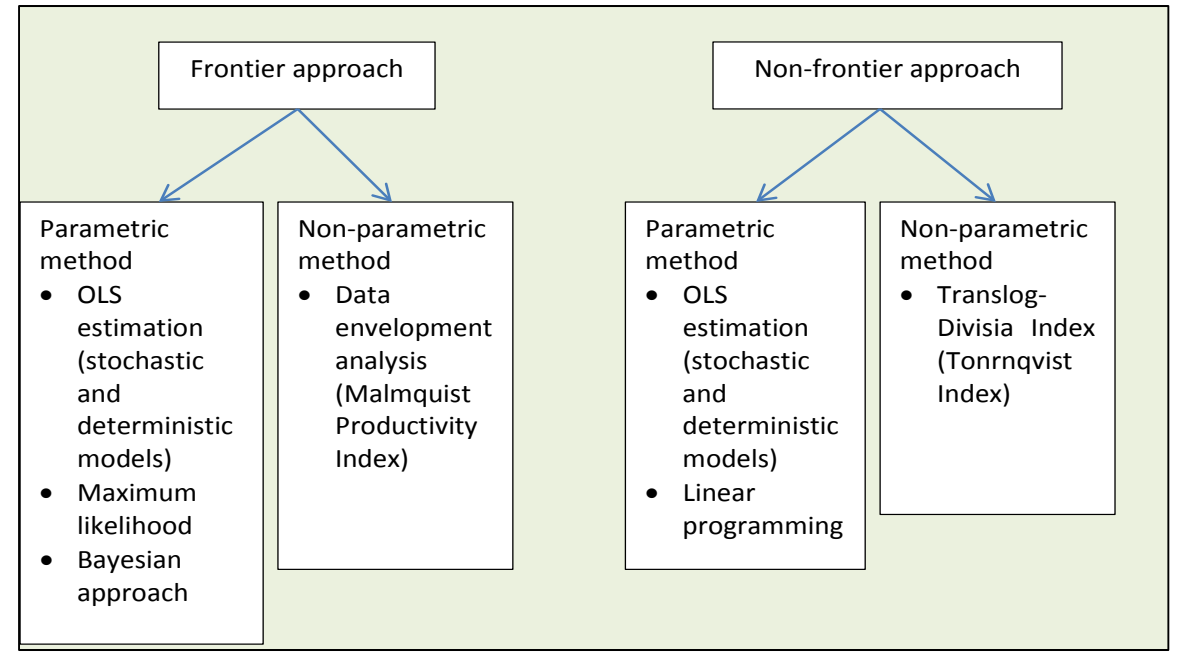

Figure 1. Approaches to Measure Total Factor Productivity Growth. Source: Own elaboration adapted from [7].

Output index:

$$
\operatorname{Ln}\left(\frac{Q_{t}}{Q_{t-1}}\right)=1 / 2 \sum_{j}\left(R_{j, t}+R_{j, t-1}\right) \operatorname{Ln}\left(\frac{Q_{j, t}}{Q_{j, t-1}}\right)
$$

Input index:

$$
\operatorname{Ln}\left(\frac{X_{t}}{X_{t-1}}\right)=1 / 2 \sum_{i}\left(S_{i, t}+S_{i, t-1}\right) \operatorname{Ln}\left(\frac{X_{i, t}}{X_{i, t-1}}\right)
$$

TFP index:

$$
\operatorname{Ln}\left(\frac{T F P_{t}}{T F P_{t-1}}\right)=\operatorname{Ln}\left(\frac{Q_{t}}{Q_{t-1}}\right)-\operatorname{Ln}\left(\frac{X_{t}}{X_{t-1}}\right)
$$

where; $R_{j, t}$ is the share of output ( $\left.j\right)$ in total revenue in time $(t)$; $Q_{j, t}$ is the output $(j)$ in time $(t) ; S_{i, t}$ is the share of input ( $\left.i\right)$ in total input cost, and $X_{i, t}$ is the input (i) in time $(t)$.

Following [14], the TFP index, defined in the last equation, is used as an approximation of technological progress, assuming no technical inefficiency.

\subsection{Total Factor Productivity Growth Decomposition: Malmquist Index}

The Malmquist index for TFP calculation is a nonparametric approach which does not require parameters estimation for the DMU (Decision Making Units) and a production technology description. TFP changes over time are estimated through changes in Malmquist productivity index. The Malmquist productivity index was first introduced by [15]. The non-parametric estimation of this Index was initiated by [16]. Comparing each firm to the best practice frontier provides a measure of its efficiency and a measure of shift in the frontier (from one period to another) which is also similar to the technological progress [16]. The Malmquist index measuring the TFP change is then a product of the latter both com- 
ponents. It is defined through a distance function measuring the TFP growth between two time periods by calculating the ratio of the distances of each data point relative to a common technology [8]. It is decomposes productivity into technical change and technical efficiency change [17]. Based on [16], the Malmquist index can be written as:

$$
m_{0}\left(y_{t+1}, x_{t+1 s}, y_{t}, x_{t}\right)=\left[\frac{d_{0}^{t}\left(y_{t+1}, x_{t+1}\right)}{d_{0}^{t}\left(y_{t}, x_{t}\right)} \times \frac{d_{0}^{t+1}\left(y_{t+1}, x_{t+1}\right)}{d_{0}^{t+1}\left(y_{t}, x_{t}\right)}\right]^{1 / 2}
$$

where $(t)$ is the initial (reference) time period and $(t+1)$ is the final period. The term $d_{0}^{t}\left(y_{t}, x_{t}\right)$ represents the distance from the period $t$ observation to the period $(t+1)$ technology. Value of $m_{0}$ higher than 1 indicates a TFP growth between both periods, while a value of $m_{0}$ lower than 1 indicates a TFP decline. The Malmquist in equation below is representing the productivity of the production point $\left(x_{t+1}, y_{\mathrm{t}+1}\right)$ relative to the production point $\left(x_{\mathrm{t}}, y_{t}\right)$. This index is in fact a geometric mean of two output-based Malmquist TFP indices; one index uses the period $(\mathrm{t})$ technology and the other period $(t+1)$ technology. To calculate this index we then need to calculate the four component distance functions, which will involve 4 linear programs (similar to thee conducted in calculating the Farrell technical efficiency measures) (see [17] for more information). The Malmquist index is particularly used in this paper to decompose the TFP growth of the agricultural sectors in the three selected countries into technical efficiency and technology changes. This decomposition can provide more accurate information about the specific sources of TFP growth.

\subsection{Understanding Factors Affecting TFP/TECH Growth}

Productivity measures do not provide any information about the separate role of each of these factors. However, an understanding of the potential sources of productivity growth is important for formulating appropriate policy decisions to increase productivity and social welfare. In the literature, there are several empirical studies exploring the impact of policies and institution, or these exogenous variables on the TFPG on a number of less developed countries includes, among others [1] [18] [19].

Recent developments in growth theory have stressed the importance of good institutions [20] [21] [22] and sound policies in creating an environment that fosters economic development through accumulation of production factors efficient use of resources. Several factors have been identified in the social science literature as the most important sources of productivity change in the agricultural sector: research and development, extension, education, infrastructure, government programs and policies, technology transfer and foreign R\&D spillovers, health, structural change and resource reallocation, terms of trade, among others.

According to the existing literature, determinants of TFPG can be organized in several conceptual variables, each of which can be operationalized with one or 
more variables. The main explanatory variables mostly used as determinants of agricultural TFP growth are research and development: [23]; extension; education and human capital; infrastructure: [24] [25] [26]; government programs and policies [27] [28] technology transfer and/or foreign research and development (R\&D) spillovers [29]; structural change and resource reallocation [30]; and terms of trade [31] [32] [33]. In fact, there is no previous evidence on the impact of all the previous factors on TFP. However, it is possible to expect a positive impact on technical change, but with diverse degrees. Some key determinants such as human capital, balanced territorial development, resource reallocation, trade liberalization and domestic inputs (infrastructure, research and development, extension and technology transfer) may conduct a more significant impact on technical change or on converse to further TFP growth. It has been a widespread belief that MENA countries TFPGs stem from two major sources: one is the trade with foreign countries, and the other is domestic inputs aiming at research, development and extension (R, D\&E) and efficiency improvement, simplified as trade liberalization and domestic inputs [18] [34] [35].

To test the above hypotheses, we adopt one step estimation procedure where the TFPG is dependant variable and mainly explained by technological change (technological progress). We estimate the impact of a multitude of variables, including trade liberalization, domestic inputs, and infrastructure, in order to get the information of contribution of each variable. Given the limitation of on the available information, the empirical analysis cover the period 1970-2012.

Hence, the model used in this study is expressed, in a stylized form, as follows (expected signs in parentheses):

$$
T E C H=\alpha_{0}+\alpha^{\prime} Z(H C, B T D, S R P, M C, R R, T O, I N F)+\mu
$$

where:

$T E C H=$ Technological Change (as principal component of TFPG) in the Tunisian (Egyptian, Jordanian) agricultural sector;

$\alpha_{0}$ : Coefficient

$Z$ : Variable vector, including:

- $H C(+)=$ Human capital-Health status measured by life expectance (years)

- $B T D(+)=$ Balanced territorial development indicators: Rural GDP per capita

- $\quad S R P(+)=$ Share of rural population (\%)

- $M C(+)=$ Main crop-Share of the main cropland harvested (\%)

- $R R(+)=$ Resources reallocation: Agricultural employment share (\%)

- $T O(+)=$ Trade Openness: $($ Import + export)/total production $(\%)$

- $\operatorname{INF}(+)$ = Infrastructure: Road density (expressed in $\mathrm{km} / \mathrm{km}^{2}$ agricultural land)

- $\mu=$ Error term, including the rest of factors that may influence TECH and they are not considered in this equation.

The Equation (5) was estimated in logarithmic form. This log-linear form allows for estimating coefficients that can be directly interpreted as elasticities. In addition, according to [36], the standard Ordinary Linear Squared (OLS) me- 
thod, if applied to non-stationary data series, that could be the case, can produce spurious regression. This form can give high $\mathrm{R}^{2}$, low Durbin-Watson (DW) statistics, and significant $t$-values of the estimated coefficients, suggesting a significant relationship between dependent and explanatory variables, when in fact they are completely unrelated. Conventionally, the factors explaining TECH are empirically analyzed by expressing variables in logarithmic form. This transformation is similar to the first differencing of variables in time series analysis frameworks. Following [37], the transformation of these variables in logarithmic terms may guarantees a stationary data.

\section{Data Collection and Sources of Data}

Statistical data for all crops and livestock products land areas, labor, machinery, animal capital, and fertilizer consumption have been collected from the FAO's annual time series during the period 1961-2012. These statistical information have been used to build agricultural outputs and inputs databases for each country. The gathered FAO information was on Total Agricultural Output (value); Seeds (in quantity and value); Machinery (in quantity and value); Pesticides (in quantity and value); Feed (in quantity and value); Capital stock (in quantity and value); Natural resources (water/land) (in quantity and value). The remaining and missing data was complemented, with labor data (in quantity and value) collected from Egyptian, Jordanian and Tunisian national statistical institutes. Data on human development index were collected from the UNDP database. Finally, the data for TFP determinant variables were collected from national and international statistical sources such as the case of human development index, and the road density.

\section{Results and Discussion}

\subsection{Törnqvist Output, Inputs, and Total Factors Productivity Indexes}

In the section below, we illustrate the principal findings issued from the Tornqvist productivity index calculation for the three respective countries, Tunisia, Egypt and Jordan. It is worth to indicate that results are covering the period 1962-2012 for Tunisia and Egypt. However, for Jordan, the analytical period is 1966-2012.

\section{Tunisian Case}

The results of the Equations (1)-(3) are presented in Figure 2. It is clear that important fluctuation over the analysis period is detected. In fact, such fluctuations are due to the volatility pattern of the Output index, which is primarily explained by the variability of rainfed agriculture in Tunisia (as caused by the high variability in climate conditions over the studied period of analysis). It is also noted an increasing trend of the output, inputs, and TFP indexes. This trend suggests technical change is not only affecting the TFP itself, but has an influence on the sustainability of the TFP growth over the whole period. Figure 2 also 


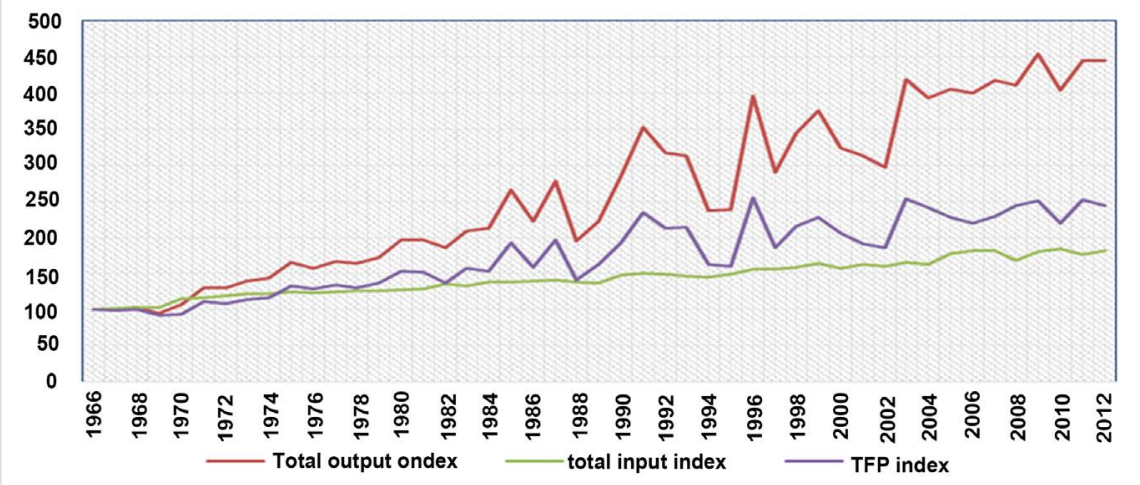

Figure 2. Törnqvist output, inputs, and total factors productivity indexes, for the Tunisian agricultural sector (1966-2012). Source: Own elaboration (2017).

shows that the input index has been multiplied by two times during the period 1966-2012. However, the output index, even though variable, has been multiplied 4.5 times during the same period, showing that the output growth was higher than the input use growth in the agricultural sector in Tunisia.

\section{Egyptian case}

The empirical findings show that trends of agricultural outputs values (both for crops and livestock) have been increased more rapidly starting 2000. Therefore, the share of agricultural revenue of the crops in the total revenue revealed considerable fluctuations during the period of analysis. Indeed, according to the FAO database [38] a decreasing pattern is noted from $69.4 \%$ in 1961 , to $61.6 \%$ in 1982 , to $55.6 \%$ in 1984 and then increased to $71.5 \%$ in 1992 . The same fluctuating trend for the livestock revenue was also manifested. The share in values increased from $30.7 \%$ in 1961 , to $38.4 \%$ in 1982 , to $44.4 \%$ in 1984 and then decreased to $28.6 \%$ in 1992 . From the input growth perspective, the labor, fertilizers, capital stock and seeds values have been strongly increased since 1990. All these variabilities lead to the changeability on the annual growth rates of the selected agricultural inputs and outputs (Figure 3).

\section{Jordanian case}

The annual average growth rates in the total output index (TOI), total input index (TII) and total factor productivity index (TFPI) between 1966 and 2012 are shown in the Figure 4. The results estimated for individual years appeared to vary widely because of fluctuations in the prices of inputs and outputs. The TFP index shows an important fluctuation over the analysis period. This fluctuating trend is mainly due to the fluctuation of the Output index, which is explained by the variability of rain-fed agriculture in Jordan due to highly variable climate conditions. Empirical results indicated that inputs and outputs variables are ranging between $0.7 \%$ (e.g., natural resource quantity) and $18.2 \%$ (e.g., fertilizers values). Thus, the increase on production or outputs is the result form the use of traditional factors of production such as cultivated areas and little contribution from modern inputs (fertilizers and machinery) to the agricultural output growth is illustrated. Moreover, the findings show also an increasing trend 


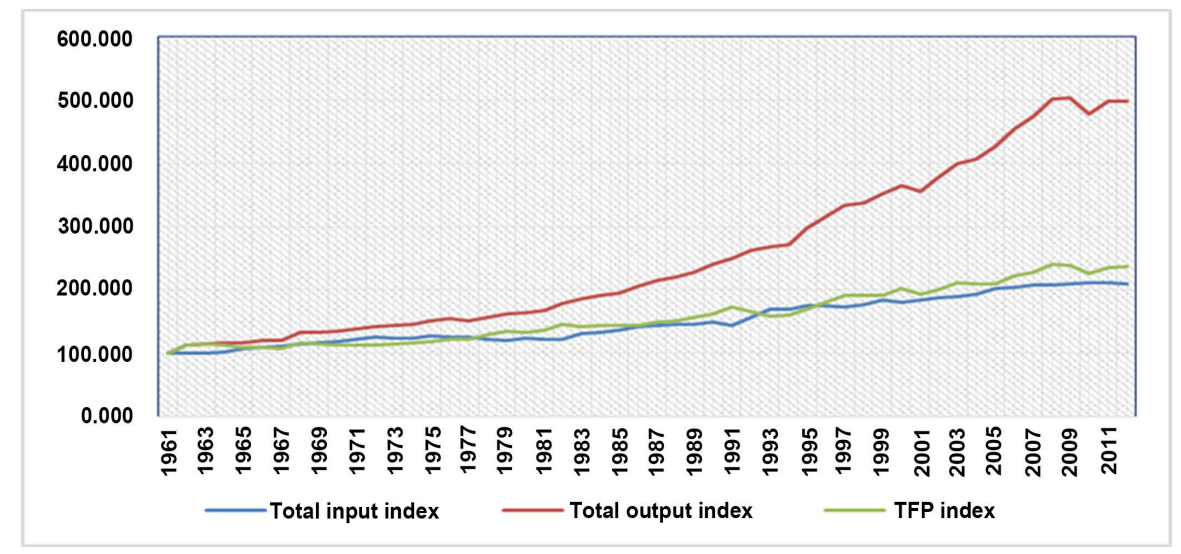

Figure 3. Törnqvist output, inputs, and total factors productivity Indexes, for the Egyptian agricultural sector (1962-2012). Source: Own elaboration (2017).

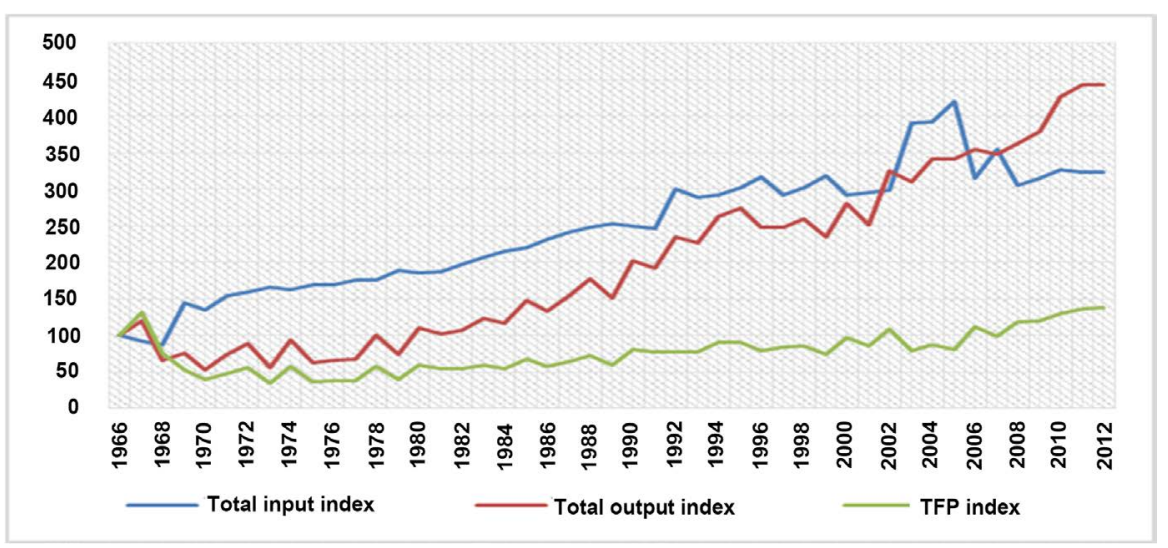

Figure 4. Törnqvist output, inputs, and total factors productivity indexes, for the Jordanian agricultural sector (1966-2012). Source: Own elaboration (2017).

of the output, inputs, and TFP indexes in Jordan. However, these values should be further analyzed in order to investigate the components the TFP growth and attributes clear shares to the different growth sources.

The comparison between both periods 1962-2012, and 2000-2012 shows that technology change has speeded up in Tunisia and Jordan during the later period, but was stable in Egypt for both periods. As a result, TFP growth is much higher during the last period in Tunisia and Jordan with respective values of $9.1 \%$ and 9\% (Figure 5).

\subsection{TFP Growth Decomposition-Malmquist Index: Efficiency Change and Technological Progress}

The objective of using the Malmquist Index was to be able to decompose the TFP growth into different components, and further understand the origin of such a growth. Results of MI calculations shows different growth patterns of agricultural productivity in the three selected countries (Figure 6). While TFP growth in Tunisia and Jordan was a mix of growth in efficiency, technology, and scale changes, the Egyptian agriculture rather shows a growth of productivity 


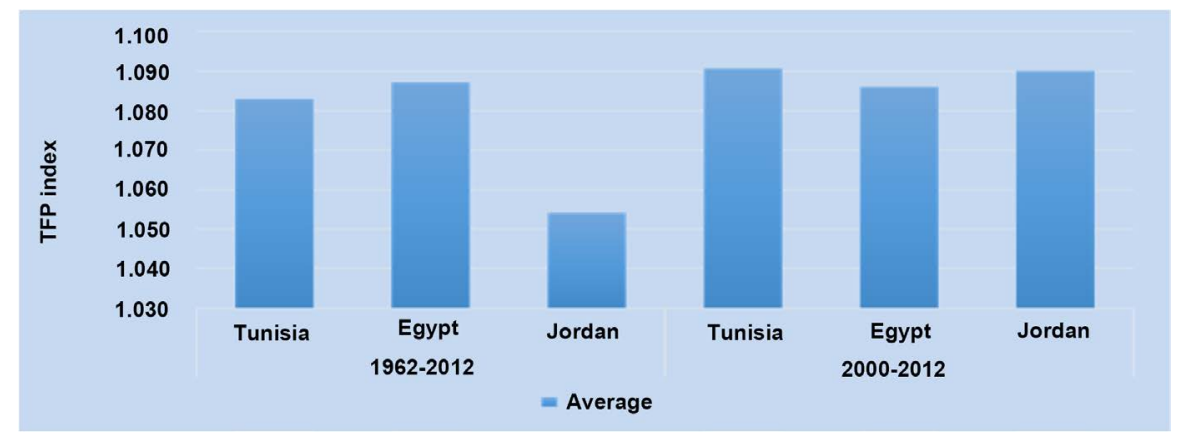

Figure 5. Cross countries comparison of TFP change for both periods 1962-2012, and 2000-2012. Source: Own elaboration (2017).
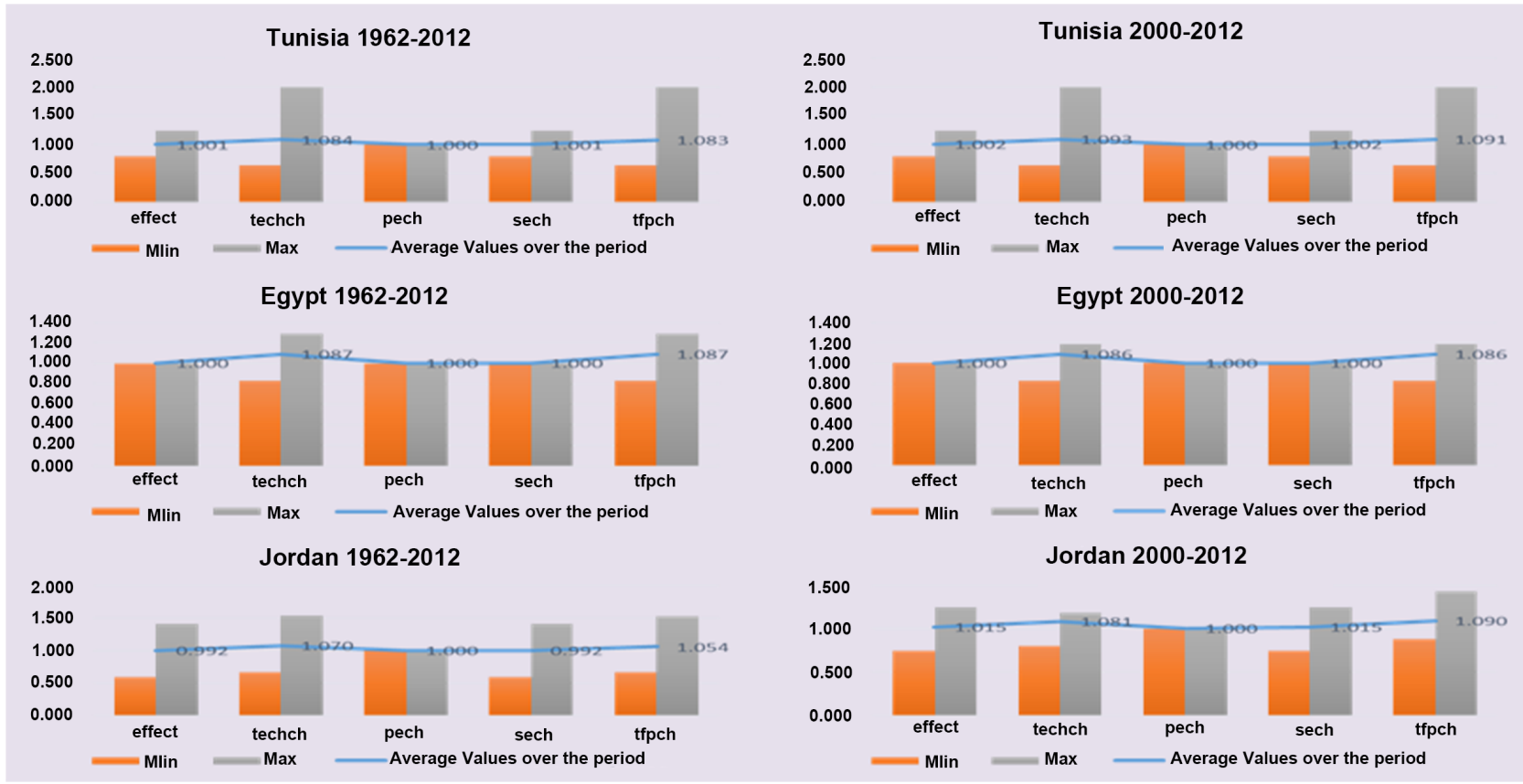

Figure 6. Efficiency change (EffCh), Technology change (Techch), pure efficiency change (Pech), scale efficiency change (Sech), and TFP change (Tfpch) for Tunisia, Egypt, and Jordan during the periods 1962-2012, and 2000-2012. Source: Own elaboration (2017).

exclusively based on technology change. Results also shows that annual TFP growth rates over the period 1962-2012 were about 8.3\%, 8.7\%, and 5.4\% in Tunisia, Egypt, and Jordan, respectively.

\subsection{Determinants of TECH Growth}

Results from the estimation of Equation (5) are displayed in the table below (Table 1). This is an attempt to test the relationship between various factors and rate of TFP growth proxied here by the TECH indicator. From statistical point of view, the three models are valid as $\mathrm{R}^{2}$ is acceptable and the f-statistic is significant which indicates the overall significance of the three estimated models. The human capital indicator has a positive relationship on TECH growth. The coefficient is positive and statistically significant at $10 \%$ level. Economic theory 
Table 1. TECH Determinants in the Tunisian, Egyptian and Jordanian Agricultural Sectors (1970-2012).

\begin{tabular}{cccc}
\hline & \multicolumn{3}{c}{ Dependent variable LTECH } \\
\cline { 2 - 4 } & Model-Tunisia & Model-Egypt & Model-Jordan \\
\hline Intercept & 0.014 & $0.05^{*}$ & $0.04^{\star}$ \\
LHC (Human capital) & $0.95^{* *}$ & $1.39^{* * *}$ & $3.91^{* * *}$ \\
LBTD (Balanced territorial development) & $-0.15^{* *}$ & $-0.08^{* * *}$ & $-0.65^{*}$ \\
LSRP (Share of rural population) & $-0.83^{*}$ & $-3.04^{* * *}$ & $0.85^{* *}$ \\
LMC (Share of main cropland harvested) & $0.17^{* * *}$ & $0.35^{* *}$ & 0.06 \\
LRR (Resources reallocation-Agricultural & $0.32^{* *}$ & $0.83^{* *}$ & -1.25 \\
employment share) & -0.015 & 0.06 & $-0.17^{* * *}$ \\
LTO (Trade openness) & -0.021 & -0.03 & 0.05 \\
LINF (Infrastructure) & Statistical \& Econometric Indicators \\
\hline T & 43 & 43 & 43 \\
$R^{2}$ & 0.43 & 0.37 & 0.32 \\
F-statistic & $3.79(\mathrm{p}<0.0036)$ & $2.95(\mathrm{p}<0.015)$ & 2.43 (p $<0.038)$ \\
Log-Likelihood & 93.37 & 91.23 & 66.03 \\
\hline
\end{tabular}

Source: Own elaboration form Equation (5) and database (2017). Note: ${ }^{*}{ }^{* *}, * * *$ are significant level at 1,5 , and $10 \%$, respectively.

has thus recognized two explicit channels that allow human capital to influence agricultural economic development. A direct channel, in which human capital is a direct factor of production, contributing directly to output, and an indirect channel, in which human capital serves as a stimulus to technological change.

Given that technological progress may come to be the most important long-run driver of TFP growth, especially as economies reach the developmental frontier, in the long-run this source of human capital's impact on TECH growth is the most invariant, and potentially the largest impact human capital can have on the agricultural sector economic development. This implies that output can grow directly due to the increase on human capital stocks as well as augmentation of physical capital, labour and technology. Through the augmentation of the effective labour force in spillover models through investment in physical capital, or the growth in technology due to human capital devoted to research, the human capital factor is considered as and important driver of technological change and hence development has emerged as potential factor explaining the agricultural productivity growth in the studied countries.

The balanced territorial development indicator, measures as rural GDP per capita has a negative impact on TECH growth. The coefficient is negative in the three cases and significant at 5\%,10\% and 1\% level for Tunisia, Egypt and Jordan, respectively. The estimate implies that an increase in the rural GDP per capita by one percentage point, leads to a $0.15,0.08$ and 0.65 points decrease in 
TECH. There is no doubt that development of agriculture in the three countries can play a direct role in rural poverty alleviation, since the majority of rural poor depend on agricultural activity for providing the main source of their income and employment. It also contributes indirectly to alleviate rural poverty because the state of agriculture influences that of the non-farm rural economy.

With regard to this negative relationship between technological change and rural poverty (proxied by rural GDP), the empirical evidence seems to lend support that technological change in agriculture can alleviate poverty both directly by raising the welfare of poor farmers who adopt the new technological innovation, as well as indirectly through the effects on the price of food for net buyers, and labor effects in agriculture. It is, therefore, possible for agricultural growth to be associated with worsening of the distribution of income. If, moreover, the deterioration is sufficiently severe, it can even cause parts of the rural population to become poorer in absolute terms, mainly for Jordan. This result indicates that agricultural activity is still a marginalized activity which is linked to low levels of income and is a source of employment for low productive labor. This type of structural problem cannot be handled solely within the framework of an agricultural development strategy but implies a wider vision of integrated rural development where agriculture is developed in parallel/synergy with other economic sectors.

The impact of rural population on the TECH is different between the three countries. While, the coefficient is significant at different levels, this relationship is negative for the Tunisian and Egyptian cases. In contrast, this liaison is positive for the case of Jordan. In light of this, an increase in the share of rural population by one percentage point, leads to $0.83 \%$ and $3.04 \%$ decrease on TECH in Tunisia and Egypt, respectively with an increase for around $0.85 \%$ on Jordanian TECH. It is clear that demographic factors help to explain why some technologies fail to be transmitted. Certain technologies are inapplicable in some MENA areas with a small population, others require high population density and this depend on the technology.

Moreover, demographic factors also provide motivation for development. The fundamental changes in the relation between human and natural resources occur in areas with high population growth rates. The highest coefficient is found to be in Egypt. This is may be due to the fact that rural population increases was accompanied by slow technological change, resulting, radical change in the patterns of agricultural productivity growth. Regarding the relationship between the share of the main cropland harvested in each country and the TECH, empirical findings showed the potential explanatory for this variable on the increase of TECH. The share of wheat cropped area compared to the total cropped area (and expressed in percentage) is positively and significantly correlated with the TECH of both Tunisian and Egyptian sector. This result is highly important if we consider that wheat is already stated as among the most strategic crops for both countries. The wheat sector is in fact highly subsidized from both consum- 
er and producer sides, and the yields are largely below the standard potential of the two countries. The estimated coefficient, expressing the TECH elasticity of the wheat area in the two cases is also high showing that the effect of this variable is large. This highlighted the need to develop new and tolerant varieties to drought, disease, and heat accompanied with an enhancement of their adoption by farmers in the two targeted countries.

As expected, the estimated results indicate that resource reallocation (measured as agricultural employment share) has positive and significant impact on TECH in Tunisia and Egypt, and consequently on TFP. In contrast this coefficient is negative and no significant for the Jordanian case. The positive correlation suggest that an increase of 1 percent of the agricultural employment share, leads to an increase for 0.32 and 0.83 points in TECH, and consequently TFP for both countries, respectively. It is evident true that agriculture and the rural sector have been a major source of employment. However, over the past three decades the share of agriculture in their respective gross domestic product (GDP) has been declining steadily in favour of other sectors. Moreover, these trends are evidenced by the increasing migration of labour to urban sectors and the decreasing contribution of agriculture to total employment and to GDP. A decline much faster than its decline as an employment provider sector. As consequence, this trend away from agriculture has not necessarily been matched by employment in non agricultural sectors such as manufacturing, tourism and services. This would suggest, taking into consideration the empirical findings, that employment in agriculture should increase in Tunisia and Jordan and other employment should reduce while TECH in agriculture is better in rural areas.

A number of empirical studies indicated that agricultural economic growth is affected by the degree of trade openness (TO) and on other hand cause increasing degree of business. In addition, there is a common opinion that trade openness remains potential factor on explaining TECH growth. Empirical findings show a negative and significant relationship between TO and TECH in the Jordanian case. In reality, we expect a positive causality between the two variables. Therefore, such impacts are even negative or no significant with a low magnitude of the corresponding coefficients. This may be due to the deterioration of the terms of trade that our targeted countries experienced in the last three decades. This deterioration will, definitively, lead to compel the economy to decrease its final demand as the cost of imported goods increase, a development that does not favor TECH growth. Such findings confirms the results in Schiff and Valdéès (1992) where trade policies that lowered agriculture's terms of trade have been a major cause of the slow growth in developing countries-precisely the opposite of the intended effect from industry-led growth strategies. While there is a common consus on the significant role that rural infrastructure can play in improving agricultural productivity in developing economies, our findings indicates a no-significant and negative, in both Tunisian and Egyptian cases, relationship between this variable and TECH. This might indicate a low integration of farmers within large neighboring markets. Rural roads provide the important 
connectivity with growing markets adjacent to rural areas; they also lessen input costs and transaction costs of rural producers and consumers. Access to good infratsruce creates various income-earning opportunities for rural households and consequently provide rural households with feasible options for production, processing, marketing and distribution. Thus, it will help create the conditions for improved agricultural productivity. This highlighted the need for policy makers take a deeper look at their rural infrastructure strategy, knowing that it may affect the productivity of the agricultural sector as whole.

\section{Discussion}

\subsection{Conclusions and Implications for Raising and Sustaining Higher Agricultural Productivity Growth in MENA Countries}

\subsubsection{Concluding Remarks}

We investigate the factors that affect total factor productivity growth in MENA countries. To this end, we start first by examining levels and trends in agricultural outputs and productivity growth using Torqnovist Indexes and then computing Malmquist Indexes for three MENA countries representing three different agro-ecological areas; irrigated (Egypt), rainfed (Tunisia) and rangeland (Jordan) over the period over the period 1961-2012. The advantage of this decomposition is that allows decomposing TFP into its two components, namely technical efficiency (TEF) and technological change (TECH). The analysis was complemented by econometric regression of the obtained $\mathrm{TECH}$, considered as the most important long-run driver of TFP growth, scores on a set of explicative potential explicative variables.

The results from Torqnivist Index show an important fluctuation over the analysis period mainly for Tunisia and Jordan. This fluctuating trend is mainly due to the fluctuation of the output index, which is primarily explained by the variability of rainfed agriculture in both countries due to highly variability in climate conditions over the years. The paper also showed, as comparing the Malmquist Index between the periods 1962-2012, and 2000-2012, that technology change has speeded up in Tunisia and Jordan during the later period, but was stable in Egypt for both periods. As a result, TFP growth is much higher during the last period in Tunisia and Jordan with respective values of $9.1 \%$ and $9 \%$.

\subsubsection{Policy Implications}

The empirical findings suggest that farming activities in the three countries still need a lot of technical support, better extension, and enhancement of the comparative skills of farmers. A clear vision to promote and encourage a new generation of well-educated and specialized farmers in needed. Knowing that efficiency change had no effect on TFP means that most of the TFP growth in both countries was generated through technical change, making references to the acquisition of new technology in the farming activities.

Turning to the determinants of the components of TECH, the paper also showed that TFP can be increased due to the increasing in human capital, share 
of the main crop harvested in each country, and resource reallocation-agricultural employment share. With respect to human capital, economic theory has thus recognized two explicit channels that allow human capital to influence agricultural economic development. A direct channel, in which human capital is a direct factor of production, contributing directly to output, and an indirect channel, in which human capital serves as a stimulus to technological change. This finding highlited the need to invest in knowledge for farmers with new technologies through training and extension programs.

The main cropland harvested in each country was found to be a potential explanatory determinant on the TECH growth. This result is highly important if we consider that wheat is already stated as among the most strategic crops for Tunisian and Algeria. The wheat sector is in fact highly subsidized from both consumer and producer sides, and the yields are largely below the standard potential of the two countries. The estimated coefficient is showing that the effect of this variable is large. This highlighted the need to develop new and tolerant varieties to drought, disease, and heat accompanied with an enhancement of their adoption by farmers in the two targeted countries.

Resources reallocation proxied by the agricultural employment share was significantly and positively affecting TECH in Tunisia and Egypt. This point toward and TECH growth when the rural employment share increases. Over the past three decades the share of agriculture in their respective gross domestic product (GDP) has been declining steadily in favour of other sectors. Moreover, these trends are evidenced by the decreasing contribution of agriculture to total employment and consequently to the GDP. A decline much faster than its decline as an employment provider sector. This would suggest that employment in agriculture should increase in Tunisia and Jordan and other employment should reduce while TECH in agriculture is promising, in rural areas where agricultural activity is still a marginalized activity and still linked to low levels of income and is a source of employment for low productive labor. This type of structural problems cannot be handled only in the framework of an agricultural development strategy but implies a wider vision of integrated rural development where agriculture is developed in parallel/synergy with other economic sectors.

Finally it is worth to indicate that although the research has reached its aims, there were some unavoidable limitations. First, the item series data are limited until 2012. We recognize that we need to expend the data and include additional variables. Second, since the data used in the model is applied with the finality to understand the main factors influencing the TECH; it seems not to provide enough evidence to what extent these factors could affect the TECH. In fact, it would have been sort of objective if another variable (i.e. investment in research and development) to assess its impact on the agriculture TFP in MENA.

\section{Acknowledgements}

This work was undertaken as part of the "Agricultural Productivity with an Emphasis on Water Constraints in the Middle East and North Africa (MENA)" project 
sponsored by the Economic Research Service (ERS)-United States Department of Agriculture (USDA-https://www.ers.usda.gov/) and as part of the "Adaptation Technologies in Agriculture: Adoption and Impact Assessment of Raised bed Farming System Technology (RFST) in Egypt" project funded by the Arab Fund for Economic and Social Development (AFESD-http://www.arabfund.org/). The opinions expressed here belong to the authors, and do not necessarily reflect those of ERS, ICARDA or AFESD.

\section{Conflicts of Interest}

The authors declare no conflicts of interest regarding the publication of this paper.

\section{References}

[1] Telleria, R. and Aw Hassen, A. (2011) Agricultural Productivity in the WANA Region. The Journal of Comparative Asian Development, 10, 157-185. https://doi.org/10.1080/15339114.2011.578490

[2] Drine, I. (2011) Climate Variability and Agricultural Productivity in MENA Region (No. 2011/96).

[3] Al-Said, F.A., Ashfaq, M., Al-Barhi, M., Hanjra, M.A. and Khan, I.A. (2012) Water Productivity of Vegetables under Modern Irrigation Methods Oman. Irrigation and Drainage, 61, 477-489. https://doi.org/10.1002/ird.1644

[4] Molden, D., Oweis, T., Steduto, P., Bindraban, P., Hanjra, M.A. and Kijne, J. (2010) Improving Agricultural Water Productivity: Between Optimism and Caution. Agricultural Water Management, 97, 528-535. https://doi.org/10.1016/j.agwat.2009.03.023

[5] Dhehibi, B. and Rached, Z. (2010) Measuring Productivity Growth in Tunisian Agriculture. Causes and Consequences of Global Agriculture Productivity Growth Conference, Washington DC.

[6] Hong, W., Cao, L. and Hao, N. (2010) Trade Liberalisation, Domestic Input and Sustainability of Agricultural TFP Growth: A New Perspective Based on TFP Growth Structure. Agriculture and Agricultural Science Procedia, 1, 376-385. https://doi.org/10.1016/j.aaspro.2010.09.047

[7] Mahadevan, R. (2004) The Economics of Productivity in Asia and Australia. Edward Eldar Publishing Limited, Cheltenham.

[8] Kathuria, V., Raj., R.S.N. and Sen, K. (2013) Productivity Measurement in Indian Manufacturing: A Comparison of Alternative Methods. Journal of Quantitative Economics, 11, Nos.1\&2.

[9] Christensen, L.R. (1975) Concepts and Measurement of Agricultural Productivity. American Journal of Agricultural Economics, 57, 910-915. https://doi.org/10.2307/1239102

[10] Diewert, W.E. (1978) Superlative Index Numbers and Consistency in Aggregation. Econometrica, 46, 883-900. https://doi.org/10.2307/1909755

[11] Diewert, W.E. (1980) Capital and Theory of Productivity Measurement. The American Economic Review, 70, 260-267.

[12] Capalbo, S.M. and Antle, J.M. (1988) Agricultural Productivity Measurement and Explanation (Edited). Resources for the Future, Washington DC. 
[13] Coelli, T.J., Prasada Rao, D.S., O’Donnell, C.J. and Battese, G.E. (2005) An Introduction to Productivity and Efficiency Analysis. 2nd Edition. Springer, New York.

[14] Antle, J. and Capalbo, S. (1988) An Introduction to Recent Developments in Production Theory and Productivity Measurement. In: Capalbo, S. and Antle, J., Eds., Agricultural Productivity Measurement and Explanation, Resources for the Future, Washington DC, 17-95.

[15] Caves, D.W., Christensen, L.R. and Diewert, W.E. (1982) The Economic Theory of Index Numbers and the Measurement of Input, Output, and Productivity. Econometrica, 50, 1393-1414. https://doi.org/10.2307/1913388

[16] Färe, R., Grosskopf, S. and Lovell, C.A.K. (1994) Production Frontiers. Cambridge University Press, Cambridge.

[17] Coelli, T.J. (2008) A Guide to DEAP Version 2.1: A Data Envelopment Analysis (Computer) Program. Working Paper of the University of New England/Center for Efficiency and Productivity Analysis.

[18] Dhehibi, B., Telleria, R. and Aw-Hassan, A. (2014) Total Factor Productivity in Tunisian Agriculture: Measurement and Determinants. New Médit, 13, 4-14.

[19] Frija, A., Dhehibi and Aw-Hassan, A. (2014) Total Factor Productivity Growth of the Tunisian Agricultural Sector: A Review of Historical Trends and Main Determinants. African Journal of Economic and Sustainable Development, 4, 293-307. https://doi.org/10.1504/AJESD.2015.072699

[20] North, D. (1990) Institutions, Institutional Change and Economic Performance. The University Press, Cambridge. https://doi.org/10.1017/CBO9780511808678

[21] Hall, R. and Jones, C.I. (1999) Why Do Some Countries Produce So Much More Output per Worker than Others? Quarterly Journal of Economics, 114, 83-116.

[22] Acemoglu, D., Johnson, S. and Robinson, J.A. (2001) The Colonial Origins of Comparative Development: An Empirical Investigation. The American Economic Review, 91, 1369-1401. https://doi.org/10.1257/aer.91.5.1369

[23] King, J., Toole, A. and Fuglie, K. (2012) The Complementary Roles of the Public and Private Sectors in U.S. Agricultural Research and Development. Economic Brief 138925, U.S. Department of Agriculture, Economic Research Service.

[24] Munnell, A.H. (1992) Policy Watch: Infrastructure Investment and Economic Growth. Journal of Economic Perspectives, 6, 189-198.

https://doi.org/10.1257/jep.6.4.189

[25] Gopinath, M. and Roe, T.L. (1997) Sources of Sectoral Growth in an Economy Wide Context: The Case of U.S. Agriculture. Journal of Productivity Analysis, 8, 293-310. https://doi.org/10.1023/A:1007759705652

[26] Yee, J., Wallace, H., Mary, A. and Doris, N. (2000) Sources of Agricultural Productivity Growth at the State Level. Meeting on Agricultural Productivity. Data, Methods, and Measures, Washington DC, 9-10 March 2000.

[27] Huffman, W.E. and Evenson, R.E. (1993) Science for Agriculture. Iowa State University Press, Ames.

[28] Makki, S.S., Tweeten, L.G. and Cameron, S.T. (1999) Investing in Research and Education versus Commodity Programs: Implications for Agricultural Productivity. Journal of Productivity Analysis, 12, 77-94. https://doi.org/10.1023/A:1007855224376

[29] Isaksson, A. (2007) Determinants of Total Factor Productivity: A Literature Review. UNIDO, Mimeo. 
[30] Chanda, A. and Dalgaard, C.J. (2003) Dual Economies and International Total Factor Productivity Differences. Economic Policy Research Unit Working Paper, University of Copenhagen, Copenhagen. https://doi.org/10.2139/ssrn.404000

[31] Dantwala, M.L. (1976) Agricultural Policy since Independence. Indian Journal of Agricultural Economics, 31, 31-53.

[32] De Janvry, A. and Subbarao, K. (1986) Agricultural Price Policies and Income Distribution in India. Oxford University Press, Delhi.

[33] Ben Jemaa, M. and Dhif, M. (2005) Agricultural Productivity and Technological Gap between MENA Region and Some European Countries: A Meta Frontier Approach. Preliminary Version. http://www.erf.org.eg/CMS/uploads/pdf/1184495843_Jemaa_Dhif.pdf

[34] Bahloul, A.Q. (1999) Total Factor Productivity and Sources of Long-Term Growth in Egyptian Agriculture Sector. Egyptian Journal of Agricultural Economics, 9.

[35] Galanopoulos, K., Lindberg, I., Surrey, Y. and Mattas, K. (2008) Agricultural Productivity Growth in the Mediterranean and Tests of Convergence among Countries. 98th EAAE Seminar Marketing Dynamics within the Global Trading System: New Perspectives, Chania, 29 June-2 July 2006.

[36] Jud, D. and Hyman, J. (1974) International Demand for Latin American Tourism. Growth and Change, 5, 25-31. https://doi.org/10.1111/j.1468-2257.1974.tb00278.x

[37] Hendry, D.F. (1995) Dynamic Econometrics. Oxford University Press, Oxford. https://doi.org/10.1093/0198283164.001.0001

[38] FAOSTAT (2013) FAO Database. http://faostat3.fao.org/home/E 